\title{
Fomentar la Ciudadanía en una Sociedad Multicultural: El Multiculturalismo Canadiense Como un Modelo Político
}

\author{
Romulo F. Magsino
}

University of Manitoba

\begin{abstract}
RESUMEN
Los ataques en contra del multiculturalismo en Canadá y en los Estados Unidos han sido liderados por asimilacionistas bien intencionados y por aquéllos que se sienten amenazados por la posibilidad de que los rasgos culturales ingleses, que han sido dominantes en ambos países, sean abrumados por los elementos culturales traídos por grupos de immigrantes ethnoculturales. A pesar de que los ataques son aparentemente persuasivos, el análisis de los argumentos muestra que están basados en la carencia de entendimiento o en la ignorancia de la política de multiculturalismo. La política puede ser mejor entendida si se establece una distinción entre un estado multinacional, que incluye derechos soberanos reclamados por groupos nacionales dentro del estado, y un estado poliétnico, que tiene en cuenta derechos reclamados por los grupos culturales minoritarios. La política multicultural Canadiense se inscribe dentro de un estado poliétnico. El análisis del intento de la política multiculturalista y de sus principios constituyentes revela que es consistente con el ethos democrático de Canada; su filosofía se expresa no sólo en las piezas de legislación oficial sino también constitucionalmente en la Carta de Derechos y Libertades de Canadá. Los litigios en la corte han sostenido la posición que, dentro de la filosofía multiculturalista, la Seccion 27 de la Carta reconoce y protege los derechos de los miembros etnoculturales del país. Ciertamente, a la luz de las decisiones de la corte y de la filosofía que nutre la política multicultural, no hay bases para cuestionar una educación multicultural en la cual la educación por la ciudadanía juega un papel prominente.
\end{abstract}




\section{ABSTRACT}

Well-meaning assimilationists, as well as those threatened that the predominantly English culture in Canada and the United States will be overwhelmed by cultural elements brought by ethnocultural immigrant groups with them, have led the strident attacks against multiculturalism in both countries. Though apparently persuasive, close analysis of these attacks in Canada shows that they are based on lack of understanding or ignorance of the multiculturalism policy. The policy can be understood best by making a distinction between a multination state, with sovereignty rights claimed by national groups within it, and a polyethnic state, with polyethnic rights claimed by its cultural minority groups. The Canadian policy of multiculturalism pertains to the latter. Analysis of its intent and its constituent principles reveals that it is consistent with the democratic ethos of the country; as well, its philosophy has found expression not only in official pieces of legislation but also in the constitutionally entrenched Canadian Charter of Rights and Freedoms. Litigation in the courts sustains the view that Section 27 of the Charter, drawing from this philosophy, has given recognition to, and protection for, the rights of ethnocultural members in the country. Indeed, in light of court decisions, and the philosophy behind the policy, there is no need to worry about a kind of multicultural education in which citizenship education occupies a prominent role.

\section{RÉSUMÉ}

Les assimilationistes bien intentionnés, ainsi que ceux qui se sentent menaçés que la culture principalement anglaise au Canada et aux Etats-Unis soit accablée d'éléments culturels apportés par des groupes d'immigrants ethnoculturels avec eux, ont mené les attaques stridentes contre le multiculturalisme dans les deux pays. Même s'il semble qu'elles soient apparemment convaincantes, une analyse attentive de ces attaques au Canada montre qu'elles sont basées sur un manque de compréhension ou l'ignorance de la politique multiculturelle. On peut mieux comprendre la politique en faisant une distinction entre un état multinationale, avec des droits de souverainté revendiqués par des groupes nationalistes à l'intérieur de ses frontières, et un état polyethnique avec des droits polyethniques revendiqués par ses groupes minoritaires culturels. La politique canadienne du multiculturalisme porte sur ce dernier. Une analyse de son intention et de ses principes constituants révèle qu'elle est en accord avec la génie démocratique du pays; en plus, sa philosophie s'est manifestée non seulement dans les sections officielles de la législation mais aussi dans la Charte canadienne des droits et libertés constitutionnellement inscrite. Le litige dans les cours soutient la vue que la section 27 de la Charte, puisant son inspiration de cette philosophie, a reconnu les droits des membres ethnoculturels du pays et les a protégés. En effet, à la lumière des décisions de la cour et de la philosophie qui soutient la politique, il n'est pas nécessaire de se faire d'un genre d'éducation multiculturelle dans laquelle l'éducation sur la citoyenneté remplit un rôle important. 


\section{Introducción}

La noción ideal de ciudadanía, nos recuerda Pocock, está indisociablemente unida a dos tradiciones clásicas de la civilización occidental. ${ }^{1}$ Por un lado, la tradición griega, que germinó con la Política de Aristóteles, retrata al ciudadano como alguien que manda y es mandado. Esta tradición concibe al ciudadano como un ser humano que es, por naturaleza, cognitivo, activo e intencional, y cuya tendencia natural y fin más alto es la búsqueda inteligente de bienes prácticos conjuntamente con el otro. Dado que los seres humanos (a pesar de la restricción de ciudadanía en la democracia ateniense a los hombres libres) tienen el potencial para participar en el arte de gobernarse entre sí, la tradición griega aportó el elemento de participación política a la noción de ciudadanía.

Por otra parte, la tradición romana se centró en el individuo como posesor y manipulador de cosas o propiedades. En contraste con el ciudadano ateniense, quien interactuaba directamente con otros ciudadanos en el proceso político, la preocupación del ciudadano romano se centraba en las posesiones de, y las transacciones sobre, cosas y procesos, reguladas por la ley. Aquí, como afirma Pocock, ciudadano viene a significar "alguien libre para actuar según la ley, libre para actuar y esperar protección de la ley, un ciudadano de tal o cual comunidad legal, de tal o cual situación legal en esa comunidad"2 En suma, el ciudadano romano clásico era alguien que poseía derechos.

Así, desde las tradiciones ateniense y romana, mediante el proceso de conversión al mundo de habla inglesa, el núcleo del concepto occidental de ciudadanía en Canadá y Estados Unidos ha incluido ambos elementos de participación política y de posesión y ejercicio de derechos y responsabilidades. ${ }^{3}$ De hecho, las concepciones o definiciones de la ciudadanía a lo largo del tiempo y en diferentes países desde entonces han sido variaciones sobre el mismo tema, con énfasis en uno, o en ambos, de estos dos componentes. Ser un ciudadano consiste, principalmente, no sólo en tener derechos y responsabilidades y ejercerlos en la sociedad, sino también en participar en el gobierno y en los procesos por los que se determinan los derechos y las responsabilidades de sus miembros.

No es por ello extraño que el reconocimiento de la condición de ciudadanía haya llegado a ser un interés prioritario para los individuos y los grupos, porque les proporciona una oportunidad más completa de realizar sus vidas y bienes

1 J. Pocock, "The Ideal of Citizenship Since ClassicalTimes," in The Citizenship Debates, ed. G. Shafir (Minneapolis: University of Minnesota Press, 1998), 31-49.

2 Ibid., 37.

3 J. Ajzenstat and P. Smith, Canada's Origins: Liberal, Tory, or Republican? (Ottawa: Carleton University Press, 1995); P. Riesenberg, Citizenship in the Western Tradition (Chapel Hill, NC: University of Carolina Press, 1992). 
dentro de la sociedad. Es comprensible que se haya despertado la pasión ardiente del inmigrante marginado o de los grupos nativos, a quienes se impide la plena participación como ciudadanos totales a causa de la raza, el color, la etnia, y/o el credo. La historia moderna está llena de ejemplos de trato inhumano hacia los individuos y los grupos que no pertenecen a las capas mayoritarias o de elite que ejercen el poder en la sociedad. Las estrategias de exclusión han oscilado desde formas menores de prejuicio y discriminación, mediante el ostracismo y el aislamiento, a la absolutamente inhumana respuesta de la expulsión o matanza masivas. Pero la desventaja y la opresión se sufren y sobrellevan con resignación sólo hasta un límite. Con la conciencia política levantada y la militancia activa, los grupos étnicos minoritarios, en particular, han afirmado sus derechos de ciudadanía y, en muchos países, han movilizado sus recursos de fuerza contra la experiencia de la tiranía y la discriminación. En los primeros años de la década de los años noventa, surgió la ilusión de cambio hacia el tratamiento igualitario y la paz. Con el triunfo de la ideología democrática sobre el comunismo, la euforia global reinó por un tiempo. La caída del comunismo fue vista por muchos como la libre expansión de la democracia igualitaria y el florecimiento de la paz entre las naciones, con la protección de gobiernos participativos que asumen que la ciudadanía pertenece por igual a todos sus ciudadanos. Desgraciadamente, el optimismo se ha convertido en pesimismo y frustración, porque, uno por uno, los nuevos países autónomos se han encontrado desesperada y desvalidamente enredados en conflictos destructivos entre grupos étnicos, dentro y fuera de sus respectivas fronteras. De hecho, en todo el mundo, ha habido una marcada intensificación de conflictos no resueltos, que surgen en países donde las luchas políticas por el poder entre los grupos étnicos y el fracaso para dar satisfacción a los derechos demandados por las comunidades étnicas más débiles, ha causado enfrentamientos armados. ${ }^{4} \mathrm{~A}$ menudo, tales enfrentamientos han servido tanto para justificar la imposición de autoritarias y severas medidas militares en los países asediados, como para que los grupos dominantes consoliden su posición de poder y control.

El conflicto étnico ha asustado de manera comprensible a sociedades relativamente armónicas y estables, que ahora se ven inmersas en conflictos políticos relativos a la gestión de la diversidad cultural dentro de sus fronteras. En regímenes con tradiciones democráticas más establecidas, se han ensayado distintas vías para dar respuesta a los dilemas y problemas relativos a la tarea de relacionarse con las minorías culturales, que defienden sus identidades culturales y sus voces políticas. Por un lado, se han hecho llamamientos bienintencionados de medidas de asimilación, presumiblemente para asegurar un tratamiento igual a los grupos e individuos de las minorías culturales. Por otro, se ha oído también

4 Véase, por ejemplo, L. Diamond y M. Plattner, Nationalism, Ethnic Conflict, and Democracy (Baltimore: John Hopkins University Press, 1994); T. Gurr, Minorities at Risk: A Global View of Ethnopolitical Conflicts (Washington, D.C.: United States Institute for Peace, 1993) 
un clamor estridente a favor de la conservación y la protección del status quo, marcado por las relaciones desequilibradas entre las comunidades minoritarias y las mayoritarias.

En este artículo, intentaré mostrar que el derecho de ciudadanía de las minorías étnicas puede promoverse mediante una política basada en el multiculturalismo. Para argumentar esta afirmación, en primer lugar me referiré a las persistentes respuestas asimilacionistas y proteccionistas y a las críticas contra la diversidad cultural, que son empleadas por los críticos liberales y conservadores del multiculturalismo. Estrecharé los límites de mi argumentación, mediante la distinción hecha por Kymlicka entre minorías poliétnicas y minorías nacionales, para centrarme en el multiculturalismo canadiense, que pertenece principalmente al segundo tipo. ${ }^{5}$ Ahondando en los principios básicos que inspiran la política multiculturalista, espero disipar las preocupaciones de los críticos al respecto. Dado que, en una sociedad democrática, los principios de libertad, igualdad, y respeto y valoración mutua mediante la coparticipación cultural, están obviamente justificados, me centraré en el principio político de conservación cultural y en cómo la política canadiense de multiculturalismo apoya la plena ciudadanía para los miembros de las minorías culturales. Concluiré señalando algunas implicaciones para la educación de la ciudadanía en una sociedad multicultural.

\section{Una Perspectiva Multiculturalista en unTerror Ideológico}

La postura asimilacionista, que acepta la igualdad de los individuos y los grupos con independencia de su origen, es una respuesta popular a la diversidad cultural en los Estados Unidos. Liderados por destacados dirigentes y teóricos, los asimilacionistas de ese país han puesto su fe en la transformación de los grupos culturales minoritarios y de inmigrantes actuales, como una estrategia para promover la igualdad de oportunidades y la calidad de vida de los grupos étnicos y raciales. Para ellos, la política acomodacionista del multiculturalismo representa un impedimento a la rápida y completa asimilación de estos grupos. A pesar de que no hace mucho Glazer admitió, de mala gana, en We Are All Multiculturalists Now, que los esfuerzos asimilacionistas no han mejorado realmente las circunstancias particulares de las personas de color en el país, tal afirmación no parece haber ejercido ningún impacto sobre los asimilacionistas. ${ }^{6}$

Los bien intencionados críticos asimilacionistas estadounidenses resultan benévolos en comparación con sus colegas conservadores reaccionarios. Así, Schmidt advierte del peligro del multiculturalismo, pretendiendo demostrar que el mismo "es un moderno caballo de Troya, y que los americanos no ven ni

5 W. Kymlicka, Multicultural Citizenship: A Liberal Theory of Minority Rights (Oxford: Oxford University Press, 1995), 10-33.

6 N. Glazer, We Are All Multiculturalists Now (Cambridge, MA: Harvard University Press, 1997). 
entienden la amenaza que encierra"7 A partir de la injustificada suposición de que el multiculturalismo se basa en el relativismo cultural, Schmidt insiste en que las culturas no solamente son diferentes y desiguales, sino que también algunas de ellas son inhumanas e inmorales. Insistiendo, acríticamente, en la superioridad de la cultura occidental, rechaza la temible doctrina multiculturalista de la igualdad cultural, porque si fuera aceptada, tendría "el efecto de diluir drásticamente el actual orgullo nacional y cultural de América. Tal postura con toda probabilidad desmantelaría los 300 años de cultura del país y su influencia mundial".8

En Canadá, los sentimientos asimilacionistas emergieron con fuerza sobre todo al comienzo de los años noventa. Un miembro del Partido Reformista (Reform Party) de la Provincia de Alberta, Jan Brown, manifestó en el Parlamento la posición del partido sobre el multiculturalismo, refiriéndose a una encuesta para el Consejo Canadiense de Cristianos y Judíos (Canadian Council of Christians and Jews), poco conocida, según la cual, presumiblemente, tres de cada cuatro canadienses expresaban su preferencia por un enfoque de la inmigración al estilo estadounidense del melting pot. ${ }^{9}$ Puntos de vista similares se habían planteado anteriormente por miembros de los Conservadores Progresistas (Progressive Conservative) en el Parlamento y en las cámaras legislativas provinciales. ${ }^{10}$ En un reciente trabajo, J.L. Granatstein critica la política del multiculturalismo por promover el separatismo, y fomentar "la idea entre los inmigrantes... de que Canadá, y en particular el Canadá de habla inglesa, no tiene cultura ni nacionalidad propia."11 Cuestiona la visión del gobierno federal de que la identidad canadiense no está basada en una cultura nacional, sino en los principios de justicia, paz y solidaridad comprensiva, y defiende que tal identidad debería basarse en "la historia y el patrimonio inglés que comparten los canadienses."12 Tal y como lo ve Granatstein, "ya que los inmigrantes han venido a una sociedad ya formada, deben aceptar sus costumbres y adaptarse a sus normas", al tiempo que el gobierno debería convertir a los inmigrantes "en ciudadanos canadienses tan rápido como fuese posible, a fin de proporcionarles el conocimiento cultural que necesitan para comprender y para prosperar en nuestra sociedad".13

7 A. Schmidt, The Menace of Multiculturalism: Trojan Horse in America (Westport, CT: Praeger, 1997), 5.

8 Ibid., 39-40.

9 J. Brown, "Culture as an Individual Responsibility," in The Battle Over Multiculturalism, ed. A. Cardozo and L. Musto (Ottawa: Pearson-Shoyama, 1997), 66.

10 R. Magsino, "The Immigrant Student and Multicultural Education: Exploring the Bases of Legal Entitlement," en Education and the Law: Strengthening the Partnership, ed. W. Foster y F. Peters (Montreal: Soleil Publishing, 1990), 1.

11 J. Granatstein, Who Killed Canadian History? (Toronto: Harper Collins, 1998), 86-87.

12 Ibid, 92-93.

$13 \mathrm{lbid}, 84-85$. Also, for critiques based on a misrepresentation of multiculturalism, see S. Bissoondath, Selling Illusions: the Cult of Multiculturalism in Canada (Toronto: Garamond Press, 1994), and R. Gwyn, Nationalism without Walls (Toronto: McClelland and Stewart, 1995). 
Menos bien intencionadamente, William Gairdner manifiesta el temor a una destrucción silenciosa del Canadá inglés, como resultado de la política que va minando los valores centrales del país. Según Gairdner, Canadá ha logrado estabilidad y unidad debido a su homogeneidad y semejanza cultural y racial. Para mantener esta afortunada condición y evitar fraccionamientos, necesitamos "encontrar un sistema cultural natural que funcione, y después fomentar que todos lo asimilen, de modo que vayan perdiendo gradualmente sus diferencias previas."14 De manera que no sorprende, confía en el buen funcionamiento del sistema de gobierno y la cultura inglesa. "Fue sólo en la asimilación de altos niveles morales de libertad y responsabilidad bajo nuestras instituciones inglesas de gobierno, donde residió cualquier esperanza de disolver...[las] ponzoñosas y sangrientas diferencias" entre los canadienses. ${ }^{15}$

La preocupación por la destrucción de la cultura inglesa canadiense que subyace en las posturas de Gairdner y Granatstein exigen una rápida respuesta. En el corazón de este temor, está la nueva realidad demográfica del país. Entre 1961 y 1971, alrededor del 75\% de los inmigrantes de Canadá procedían de Europa y los Estados Unidos. Con la liberalización de las leyes de inmigración a finales de los años sesenta, que permitieron otra inmigración diferente a la de estos lugares, Canadá abrió sus puertas a nuevos procedentes de unos 200 países distintos. Ahora, sólo un quinto de los inmigrantes proviene de Europa y los Estados Unidos. Alrededor de la mitad viene de Asia, en particular de Hong Kong, Filipinas, India y China. En 1991, los canadienses con origen totalmente británico representaban sólo el $28.1 \%$ de la población; los de origen francés, el 22\%; y los de origen múltiple $u$ otros distintos, el resto. Las proyecciones indican la tendencia hacia proporciones y cantidades crecientes de los de origen asiático, especialmente a la vista de la progresiva necesidad de capital humano que contrarreste el lento crecimiento natural de la población del país. ${ }^{16}$

Esta tendencia demográfica ha dado lugar a la equivocada impresión de que la política canadiense de multiculturalismo, que apoya la conservación cultural de aquéllos que lo deseen, abre la puerta al crecimiento incontrolado de culturas minoritarias, que abrumará y traerá la defunción de la cultura canadiense inglesa.

En realidad, la política de multiculturalismo, y su implantación en las escuelas en forma de educación multicultural, no tendría por qué considerarse un asunto problemático. Nada en tal política justifica la sustitución completa, incluyendo la historia, del currículo occidentalmente orientado por un currículo afro-canadiense, ucraniano, asiático, o cualquier otro étnicamente orientado. Un currículo intelectualmente honesto tendrá que reflejar con toda seguridad las

14 W. Gairdner, The Trouble with Canada (Toronto: General Paperbacks, 1990), 392.

15 Ibid, 392-393

16 M. Kalbach and W. Kalbach, "Demographic Overview of Ethnic Origin Groups in Canada," en Race and Ethnic Relations in Canada, ed. P. Li (Don Mills, ON: Oxford University Press, 1999), 30-33. 
realidades y las instituciones tal y como se han desarrollado históricamente. Es poco probable que el desarrollo de la política de multiculturalismo intente la inclusión de más contribuciones o componentes de minorías culturales que las que están justificadas. Aunque las culturas de los grupos minoritarios en Canadá necesitan estar mejor reflejadas, a fin de remediar la ausencia de su reconocimiento en el currículo, especialmente en la historia y los conocimientos sociales, los orígenes aborígenes, ingleses y franceses del país no pueden eliminarse. El estudio de la literatura y las artes permanecerá indudablemente conectado con el sólido patrimonio occidental clásico y moderno, para que ilumine y enriquezca lo que todos aprenden. Pero, como el paisaje cultural canadiense está enriquecido por los diversos pueblos que vienen a sus costas, debería mejorarse el currículo escolar del país con la inclusión de elementos culturales apropiados y valiosos de sus grupos culturales minoritarios.

En cualquier caso, los críticos del multiculturalismo no aciertan a diferenciar lo que dice y apoya tal política, y lo que algunos partidarios estridentes y radicales del pluralismo cultural desenfrenado parecen defender. Parece que algunos críticos canadienses se dejan llevar de la discusión sobre multiculturalismo tal y como se ha desarrollado en el contexto estadounidense, y tal como de cuando en cuando se traslada de manera deformada a la situación canadiense. En los Estados Unidos, algunas cruzadas con las que los multiculturalistas radicales han pretendido denigrar el patrimonio occidental y encumbrar ciertas tradiciones culturales minoritarias, han resultado muy perturbadoras y conflictivas, especialmente en las instituciones de educación superior y en los foros públicos y educativos. ${ }^{17}$ El hecho, sin embargo, es que la retórica y la discusión estadounidenses no tienen en absoluto un equivalente considerable en Canadá, aunque algunos críticos del multiculturalismo hagan parecer como si las mismas reivindicaciones estuvieran siendo sugeridas o defendidas seriamente en este país por los grupos etnoculturales, dentro sus principios multiculturalistas de acción. Richard Gwyn cita a un poeta, Clifton Joseph, que sostiene que el objetivo de los grupos étnicos es "redefinir equitativa y realmente el país". A primera vista, el comentario es bastante aceptable, si significa tener en cuenta a los grupos étnicos marginados que aspiran a defender y trabajar por una sociedad más equitativa. Pero da la sensación de que Gwyn toma este comentario muy en serio, como prácticamente equivalente al clamor de las minorías étnicas: "su casa, a la que usted una vez me invitó, es ahora mi casa."18 La argumentación de Gwyn no aclara el contexto de la afirmación explícita de Joseph, por lo que es difícil saber lo que éste quiere decir. Aún cuando la interpretación que hace Gwyn sea la correcta, y aun cuando algunos individuos o simpatizantes de los grupos etnoculturales puedan sostener algo así, las comunidades etnoculturales, o sus portavoces, no han reivindicado nada remotamente parecido. Por supuesto, los grupos etnoculturales del país se han opuesto a la dominación y han defendido

17 P. Aulfderheide, Beyond P.C.: Toward a Politics of Understanding (St. Paul, MN: Graywolf Press, 1992); Glazer, We Are All Multiculturalists Now; J. Hunter, Culture Wars: The Struggle to Define America (New York: Basic Books, 1991).

18 Gwyn, Nationalism, 156. 
la integración y participación plenas en todos los aspectos de vida canadiense. ${ }^{19}$ Pero, precisamente, la idea de dominación cultural por el grupo - sea mayoritario o minoritario - es lo que la política canadiense de multiculturalismo pretende combatir.

Otro popular crítico del multiculturalismo, el novelista Neil Bissoondath, dedica una sección larga de su libro, Selling Illusions: The Cult of Multiculturalism in Canada, a la discusión y desacreeditación de "la corrección política", la política de la diferencia y los escritos y estudios culturales de exclusión, como si todas estas cosas formaran parte de la política de multiculturalismo. ${ }^{20}$ Tan supuestamente cosmopolita como para desatender el estudio de la corta historia del multiculturalismo en su país de adopción, Bissoondath está demasiado inmerso en la retórica estadounidense como para darse cuenta de que el multiculturalismo canadiense no tiene nada que ver con el conjunto de causas distintas que ha preocupado a los teóricos estadounidenses en las dos últimas décadas. Si bien estas causas pueden ser defendidas desde otros puntos de vista, la política canadiense de multiculturalismo se centra en las culturas minoritarias en el sentido estricto de la palabra, y en realidad no atiende a los derechos de las mujeres, o los hombres, en este sentido, los derechos de gays y lesbianas, y el derecho a derrocar tradiciones occidentales en nombre de las culturas minoritarias. También merece mencionarse aquí, puesto que Bissoondath no lo hace, que las prioridades de los teóricos radicales de las instituciones de educación superior, que pueden ser defensores del multiculturalismo, no coinciden necesariamente con las aspiraciones de los grupos etnoculturales.

La falta de conocimiento sobre esta política y, particularmente, sobre su proyección en el campo de la educación, es la causa fundamental de la representación deformada del multiculturalismo en la imagen pública. Bissoondath, quien, además de Selling Illusions, ha escrito varios artículos y ha aparecido en los medios de comunicación en acontecimientos sobre este tema, parece no haber leído ni los textos originales de la proclamación de principios de Trudeau de 1971, ni la Ley del Multiculturalismo, ni ninguno de los instrumentos legislativos al respecto aprobados por distintas provincias del país. ${ }^{21}$ Sus comentarios sobre lo que las escuelas hacen y dejan de hacer con respecto a las minorías culturales, demuestran su carencia de conocimiento sobre la educación multicultural, que ha sido un movimiento activo desde la adopción de la política de multiculturalismo. A pesar de ello, continúa lanzando diatribas contra dicha política, con tal aire de autoridad que sus lectores u oyentes, que desconocen el tema, tienen la impresión de que sabe realmente de lo que habla. Gwyn, a pesar de toda su reputación como tratadista y

19 W. Kymlicka, Finding Our Way: Rethinking Ethnocultural Relations in Canada (Toronto: Oxford University Press, 1998), 16-39.

20 Bissoondath, Selling Illusions, chap. 8.

21 P.E. Trudeau, "Statement by the Prime Minister in the House of Commons, October 8, 1971," append. en Cultural Diversity and Canadian Education, ed. J. Mallea y J. Young (Ottawa: Carleton University Press, 1984); Bill C-93, An Act for the Preservation and Enhancement of Multiculturalism in Canada, 2D Sess., 33rd Parl., 1988, cl. 3 (1) (Assented to 21 July 1988 S.C. 1988), c.31. 
periodista canadiense, se refiere explícitamente a "la introducción en los Comunes de una Ley para la Preservación y Promoción del Multiculturalismo en el Canadá", por Trudeau el 8 de octubre de 1971, y menciona erróneamente "la revisión de Mulroney y el desarrollo de la ley original del multiculturalismo en 1987".22

Es lamentable que la política canadiense frecuentemente se tergiverse por aquellos que deberían conocer mejor la situación. Indudablemente, los multiculturalistas ansiosos y algunos de sus sobre-entusiasmados aliados, llegan demasiado lejos en el celo de su causa. La situación en Canadá ha llegado a ser parecida a lo que actualmente predomina en los Estados Unidos, donde, como señala Nathan Glazer, "el multiculturalismo se ha esparcido ahora más allá de las escuelas, y más allá de su sentido primario de respeto por otras culturas".23 En general, se asocia, de forma equivocada, con causas defendidas por radicales feministas, gays y lesbianas, radicales Afro-americanos, y grupos e individuos fanáticos con quejas fundadas o infundadas contra el ethos mayoritario y el orden establecido. En consecuencia, ha llegado a ser fácil despertar la oposición generalizada contra la política canadiense mediante la denuncia de tales asociaciones. Es una lástima que escritores altamente populares, como Bissoondath y Gwyn, quienes han tergiversado completamente la política canadiense de multiculturalismo, aunque sea de forma inconsciente, hayan llegado a estar tan solicitados por los medios en las discusiones públicas sobre la misma. Hay, por lo tanto, una necesidad real de comprender íntegramente esta política tal y como es, y de evaluarla con relación a sus propios méritos.

\section{La Política Canadiense de Multiculturalismo: Definición y Principios Inspiradores}

Una importante distinción de Will Kymlicka, en su libro Multicultural Citizenship: A Liberal Theory of Minority Rights, facilita la comprensión y valoración adecuadas de la política canadiense de multiculturalismo. La distinción es entre (1) el estado multinacional y los derechos de autogobierno de las naciones componentes, y (2) el estado poliétnico y los derechos poliétnicos de sus grupos culturales minoritarios. Un estado multinacional contiene más de una de nación (o personas con una cultura común) y, así, existen culturas más pequeñas que forman minorías nacionales. Por distintas vías, voluntarias o no, esto es lo que sucede en muchos países occidentales, incluyendo Canadá (con sus poblaciones de origen inglés, francés y aborigen) y los Estados Unidos (con sus poblaciones británico-americana, indio americana, puertorriqueña y chicana). Las minorías nacionales de estos países frecuentemente declaran su soberanía, autonomía o derechos de autogobierno. Un estado poliétnico es el que tiene una serie de grupos étnicos inmigrantes, que constituyen subculturas libremente agregadas que mantienen sus características basadas en raíces culturales. Cuando defienden sus derechos poliétnicos para

22 Gwyn, Nationalism, 183.

23 Glazer, Multiculturalists Now, 13-14. 
asegurar el mantenimiento de su particularidad étnica, generalmente lo hacen dentro de las instituciones públicas de la sociedad anfitriona. ${ }^{24}$ Así, los derechos poliétnicos reclamados por estos grupos, son tanto aquellos que permiten su participación en el disfrute de los bienes disponibles para los grupos e individuos de la cultura dominante de la sociedad, como los que les permiten mantener y apoyar lo que les caracteriza como minorías culturales. Como indica Kymlicka, son integradores, pero también diferenciadores. Se reclaman porque los grupos minoritarios y sus miembros quieren asegurar su lugar dentro del orden social sin abandonar su carácter como grupos culturales distintivos. La comprensión de que los derechos que reclaman los individuos y los grupos étnicos, son típicamente derechos poliétnicos, más que de autogobierno, disipará significativamente los erróneos comentarios de que la política candiense de multiculturalismo, al reconocer tales derechos, los margina, aísla, o encierra en guetos separados del resto de la sociedad. En cualquier caso, debido a que esta política en sí misma parece ser frecuentemente mal entendida y poco apreciada, es preciso presentar más explícitamente los propósitos y principios que la inspiran.

El término "multiculturalismo" ha sido utilizado con una gran imprecisión lingüística. Esto no puede cambiarse, dado el número y diversidad de sus usuarios. También, como indica Glazer con gran perspicacia en este mismo sentido, en el contexto estadounidense ha crecido hasta convertirse en una categoría o causa que incluye todo los que se refiere a los grupos minoritarios, culturales o no. ${ }^{25}$ Así, es poco probable que cualquier esfuerzo que pueda hacerse para limitar su uso, dé lugar a una definición que sea suficientemente precisa y abarcadora para satisfacer a todos sus usuarios. Ahora bien, alguien que recomienda algo relativo a los otros necesita identificar, con tanta precisión como sea posible, qué es lo que está recomendando. Afortunadamente, en contraste con la fluidez de significados asociados a los términos en su uso ordinario, "multiculturalismo" en Canadá tiene también un significado mucho más preciso, relacionado especialmente con la política e instituciones gubernamentales.

En Canadá, la política de multiculturalismo se entiende como un instrumento para la integración de los grupos étnicos, mediante la legitimación y promoción de las aspiraciones de sus miembros a participar en la sociedad y a conservar al mismo tiempo elementos de su patrimonio cultural. La concepción canadiense del multiculturalismo quedó establecida inicialmente en la declaración del antiguo Primer Ministro Pierre E. Trudeau, presentada a la Cámara de los Comunes el 8 de octubre de 1971. Después de declarar que su gobierno había aceptado las recomendaciones de la Comisión Real sobre Bilingüismo y Biculturalismo - tal como se contienen en el Volumen IV de su Informe y según se dirigieron a instituciones y órganos del gobierno - afirmó: "La libertad del individuo quedaría suprimida si se le encerrase de por vida dentro de un determinado compartimento por la 
circunstancia accidental del nacimiento o idioma"26 Para resaltar el propósito de su política, en el último párrafo de su declaración volvió a reiterar:

Deseo subrayar la visión del gobierno de que una política de multiculturalismo dentro de una estructura bilingüe es básicamente un apoyo consciente a la libertad individual de elección. Somos libres para ser nosotros mismos. Pero esto no puede ser dejado al azar. Debe ser buscado y fomentado activamente. Si la libertad de elección está en peligro para algunos grupos étnicos, está en peligro para todos. La política de este gobierno es eliminar cualquier peligro como ese y "salvaguardar" esta libertad. ${ }^{27}$

Adoptamos una política que asegura la "libertad cultural de los canadienses", afirmaba también Trudeau, señalando:

Tal política debería ayudar a acabar con las actitudes discriminatorias y las rivalidades culturales. La unidad nacional, si tiene que significar algo en el sentido profundamente personal, deberá estar basada en la confianza en la identidad individual propia de cada uno; esto hará crecer el respeto hacia lo de otros y la buena voluntad para compartir ideas, actitudes y creencias. Una política enérgica de multiculturalismo ayudará a crear esta confianza inicial. Puede proporcionar los cimientos de una sociedad basada en un trato justo para todos. ${ }^{28}$

Los dos textos citados contienen la especificación de los principios o posiciones de valor que se consideran justificables en una sociedad culturalmente diversa, como Canadá: la libertad de elección, que incluye la conservación cultural; la unidad nacional; el respeto mutuo, basado en la confianza en la identidad cultural de cada uno y en la cultura compartida; y la igualdad, o trato justo para todos.

Sentados los valores que se pretenden con la política propuesta, Trudeau explica la estrategia general de esa política del siguiente modo:

El gobierno apoyará y fomentará las diversas culturas y grupos étnicos que dan estructura y vitalidad a nuestra sociedad. Se le animará a compartir sus valores y expresión cultural con otros canadienses y contribuir así a una vida más rica para todos. ${ }^{29}$

Esta estrategia general quedaba plasmaba explícitamente en un un plan de cuatro puntos para el gobierno federal y sus instituciones.

26 Trudeau, "Statement," 518.

27 Ibid., 520.

28 Ibid., 519.

$29 \mathrm{lbid}$. 
Pasaron diecisiete años antes de que el gobierno federal pudiera traducir legislativamente la política de multiculturalismo dentro de un marco bilingüe. Sin embargo, el paso del tiempo no disminuyó el compromiso gubernamental con los valores canadienses fundamentales enunciados en la declaración original. En 1988, la Cámara de los Comunes aprobó la Ley para la Conservación y Promoción del Multiculturalismo, la cual afirma, entre otras cosas, lo siguiente:

3. (1). Por la presente se declara que la política del Gobierno de Canadá se dirigirá a:

(c) promover la participación plena y equitativa de los individuos y las comunidades de cualquier origen en el permanente desarrollo y cooperación en todos los aspectos de la sociedad canadiense, y ayudarles en la eliminación de cualquier obstáculo que dificulte tal participación....

(e) asegurar que todos los individuos reciban igual tratamiento e igual protección bajo la ley, respetando y valorando su dignidad;

(f) fomentar y ayudar a las instituciones sociales, culturales, económicas y políticas canadienses para que todas respeten y tengan en cuenta el carácter multicultural de Canadá;

(g) promocionar la comprensión y creatividad que nacen de la interacción entre individuos y comunidades de orígenes diferentes. ${ }^{30}$

Estas disposiciones se hacen eco de otras que pueden encontrarse en instrumentos legislativos o declaraciones políticas aprobadas anteriormente por diferentes gobiernos provinciales. ${ }^{31}$ Una norma legal provincial de Manitoba destacará posteriormente estos mismos valores del siguiente modo:

Por la presente se declara que la política del Gobierno de Manitoba se dirigirá a:

(b) reconocer y promover los derechos de todos los habitantes de Manitoba, con independencia de su cultura, religión o antecedentes raciales, para

(i) tener igualdad de acceso a las oportunidades

(ii) participar en todos los aspectos de la sociedad, y

(iii) respetar sus valores culturales, $y$

30 Bill C-93, Multiculturalism in Canada Act.

31 R. Magsino and A. Singh, Multicultural Education in Newfoundland and Labrador: A Survey of Practices, Policies, and Conceptions in Canada (St. John's: Memorial University of Newfoundland, 1986). 
(c) promover las oportunidades de la sociedad multicultural de Manitoba, actuando conjuntamente con todas las comunidades culturales y estimulando la asociación y la cooperación entre ellas. $^{32}$

Si tal política ha tenido efectos de separación, es un indicio de que determinados segmentos de la población canadiense se niegan a aceptar las aspiraciones de los grupos étnicos y sus miembros a la participación o a la conservación cultural, o a ambas cosas. Es importante señalar que la separación no tiene su origen en los individuos o en los grupos étnicos en sí mismos, que, claramente, no quieren separar sino, más bien, pertenecer. Su deseo de participar dentro de la sociedad canadiense y su contribución al desarrollo del país resultaban obvios para la Comisión Real sobre Bilingüismo y Biculturalismo, cuyas recomendaciones sirvieron como base para la política enunciada por el Sr. Trudeau. ${ }^{33}$

En vista de la consistencia de los valores e intenciones asumidas en la declaración inicial sobre multiculturalismo, la Ley Federal de Multiculturalismo y las políticas y legislaciones provinciales, la frecuente afirmación de que el concepto de multiculturalismo puede definirse o se ha definido al gusto de cada cual, resulta bastante irrelevante. El multiculturalismo, al menos como postura de los gobiernos canadienses con respecto a la realidad multicultural del país, se refiere a algo muy preciso, y cualquiera que se aparte de ello estará hablando de otra cosa. Aunque al establecer una definición se corre el riesgo de no decir nada o caer en la polémica, ofrezco la siguiente definición operativa: El multiculturalismo canadiense significa la aceptación de, apoyo para, e implantación, en órganos e instituciones gubernamentales, de los principios de libertad de conservación cultural, igualdad y respeto mutuo a través de la coparticipación cultural, a fin de promover la unidad en la sociedad canadiense.

\section{Fomentar la Ciudadanía Mediante la Política de Multiculturalismo}

Ciudadano es, por definición, quien posee derechos y a quien corresponden obligaciones en la sociedad. Ahora bien, la historia política nos enseña que estos derechos y obligaciones no se establecen de forma que aseguren condiciones justas para todos. El velo de la ignorancia, que John Rawls prescribe para la formulación de los principios imparciales de justicia, que son necesarios para guiar el establecimiento y acción de las disposiciones e instituciones sociales, no es válido en ninguna parte para nosotros los mortales, ni ahora ni en ningún tiempo

32 Manitoba Legislative Assembly, Bill 98, The Manitoba Multiculturalism Act, 3rd Session, 35th Parl., 1992 (assented to 24 June 1992, S.M. 1992, c.56).

33 Trudeau, "Statement," 218. 
pasado o futuro. ${ }^{34}$ La realidad es que cada estado tiene que elaborar su propio conjunto de principios, que gobierne la vida de su población e instituciones.

En favor de la justicia para los grupos culturales minoritarios, Canadá ha decidido formular e implantar su política de multiculturalismo. El país ha sido justamente elogiado por emprender un valiente experimento en el tratamiento político de su población culturalmente diversa. Pero incluso cuando esta política busca la justicia para los grupos minoritarios, su principal objetivo se sitúa en la unidad nacional, la cual, para Trudeau, vendría dada por la acomodación de los sentimientos expresados con cierta pasión por determinados grupos etnoculturales, que hicieron declaraciones o remitieron escritos a la Comisión Real sobre Bilingüismo y Biculturalismo. Sin embargo, con independencia de que a veces sea o no asumido, la política canadiense de multiculturalismo es también la mayor declaración política que apoya la condición de plena ciudadanía para los miembros de comunidades etnoculturales del país. Como señala Jacques Hebert, esta política "reconoció el derecho de cada canadiense a vivir y realizarse en la cultura de su elección, y de cada grupo étnico...a preservar su propio patrimonio cultural y lingüístico respetando los derechos de los demás"35 Tal política, añadía, refrenda el principio según el cual "una sociedad libre y justa debe aceptar el pluralismo y permitir que cada ciudadano haga una elección personal del estilo de vida, costumbres y cultura idónea, provengan o no de su propio grupo étnico".36

No es necesario decir que la adopción de esta política no sólo ha orientado la legislación federal y provincial sobre multiculturalismo, sino también, y aún más importante, la incorporación del principio de multiculturalismo en la ley suprema del territorio. Como un elemento firmemente afianzado en la Constitución Canadiense, la Carta de Derechos y Libertades establece en su Sección 27 que "Esta Carta será interpretada de manera coherente con la preservación y promoción del patrimonio multicultural de los canadienses".37

La Sección 27 claramente ha proporcionado protección a las minorías culturales del país. Así, en el fallo de R. v. Big M Drug Mart Ltd., que trataba la violación de la ley federal sobre los días festivos (Lord Day's Act), el Tribunal Supremo sostuvo que la ley era inconstitucional porque infringía la libertad de conciencia y de religión de los acusados. Al considerar inconstitucional la exigencia de la ley de cerrar todas las tiendas en domingo por ser un día de descanso, el Tribunal decretó que la práctica mayoritaria (Cristiana) no puede ser impuesta a ciudadanos con ideas diferentes. Como señaló el juez Dickson,

34 J. Rawls, A Theory of Justice (Oxford: The Clarendon Press, 1972).

35 J. Hebert, "Legislating from Freedom," en Toward a Just Society, ed. T. Axworthy and P.E. Trudeau (Markham, ON: Penguin Books Canada, 1990), 138.

36 Ibid.

37 House of Commons, Canadian Charter of Rights and Freedoms, s.27, Part I of the Constitution Act, 1982, being Schedule B to the Canada Act 1982 (U.K.), 1982, c.11. 
Consideramos que aceptar que el Parlamento mantenga el derecho de obligar a una práctica universal del día de descanso elegido por una religión, no es coherente con la preservación y promoción del patrimonio multicultural de los canadienses. Hacer eso contradice lo establecido en la Sección $27{ }^{38}$

Además de permitir a los grupos culturales minoritarios expresar sus prácticas culturales, lo estipulado en la Carta también ha ayudado a proteger la integridad de estos grupos. Así, en R. v. Keegstra, relativa a la presunta violación del Código Penal, el cual prohibe la promoción intencionada del odio contra un grupo determinado, el Tribunal Supremo de Canadá corroboró el fallo del Tribunal de Apelación de Alberta, el cual aplicó la S. 27 para interpretar la S.2 (b) de la Carta, sobre libertad de palabra y expresión. Confirmando la disposición del Código Penal, que penaliza la promoción intencionada del odio, el Tribunal declaró lo siguiente:

El valor expresado en la S.27 no puede ser pasado por alto al considerar la validez de la S.319(2) (del Código Penal) bajo la S.1 (de la Carta), y consideramos que la S.27 y la obligación de una visión multicultural de nuestra nación nos obligan a enfatizar la gran importancia que tiene el objetivo de erradicación de la propaganda del odio de la sociedad. ${ }^{39}$

El impulso del fallo en el caso Keegstra ha sido mantenido de forma clara por el Tribunal Supremo en Canadá (Canadian Human Rights Commission) v. Taylor, que rechazó el recurso de los apelantes contra una disposición del Código Canadiense de Derechos Humanos, bajo el cual su conducta se consideró como exposición de un grupo de personas al odio o el rechazo debido a la raza o la religión. ${ }^{40}$ En R. v. Andrews, el Tribunal confirmó que la Carta, a través de la Sección 27 , ha recogido la riqueza, profundidad y dinamismo de la sociedad canadiense y ha constitucionalizado su importancia. ${ }^{41}$ Esta Sección ha proporcionado una clara dirección a la hora de aplicar la Sección 1 de la Carta, de modo que las leyes apropiadas para la protección del multiculturalismo, se convierten en límites razonables a la libre expresión. La postura del protección del Tribunal Supremo también ha sido manifestada en el caso $R$. $v$. Tran, en el cual el Tribunal falló que no proporcionar la traducción completa de todos los testimonios de un juicio a un acusado constituye una infracción de la Sección 14 de la Carta. ${ }^{42}$ Para el Tribunal, el derecho a un intérprete forma parte del derecho del acusado a disfrutar de un juicio justo e imparcial, y también de la pretensión de nuestra sociedad de ser multicultural, tal como se expresa en la S.27 de la Carta. De hecho, este fallo producido en el nivel judicial superior ha repercutido necesariamente en casos

38 R. v. Big M Drug Mart. (1985). 1 S.C.R. 295. p. 519.

39 R. v. Keegstra. (1990). S.C.R. 697. p. 57.

40 Canada (Canadian Human Rights Commission) v. Taylor. (1990). 3 S.C.R. 892.

41 R. v. Andrews. (1990). 3 S.C.R. 870.

42 R. v. Tran. (1994). 2 S.C.R. 951. 
de niveles más bajos. Está claro que la política canadiense de multiculturalismo, apoyada primero oficialmente en las declaraciones políticas y la legislación, y luego como artículo afianzado en la Carta de Derechos y Libertades, ha producido beneficios concretos para los ciudadanos canadienses que pertenecen a comunidades etnoculturales.

\section{Algunas Implicaciones en la Educación para la Ciudadanía}

Por definición, la educación para la ciudadanía no puede ignorar el desarrollo de la capacidad de participación que se requiere en el ciudadano. En consecuencia, hay que valorar muy positivamente el renovado interés por el estudio de los niños como ciudadanos participantes ${ }^{43}$ - de los procesos por los cuales demuestran sus habilidades para discutir, cuestionar, debatir y participar activamente; y las condiciones bajo las cuales se producen estos procesos - No es necesario decir que sobre este tema se ha escrito mucho, y se va a escribir mucho más.

Sin embargo, el contenido sustantivo de las capacidades del ciudadano y la comprensión plena de los derechos y responsabilidades de los ciudadanos son igual de importantes y no pueden pasarse por alto. Los diseñadores curriculares que esperan desarrollar la educación para la ciudadanía deben asegurar la inclusión de materiales y experiencias que favorezcan, en el mayor grado, la formación de ciudadanos informados y sensible, que sean conscientes de los contextos, privilegios y exigencias de la ciudadanía. Así, un objetivo en toda regla de la educación para la ciudadanía no puede ser otro que el de un esfuerzo comprensivo de desarrollo curricular, lo que está no sólo más allá del alcance de este artículo, sino también de las posibilidades del autor. No obstante, debemos tratar un asunto importante, derivado de las críticas de Gairdner, Granatstein y Gwyn. Una educación para la ciudadanía multiculturalmente orientada ¿desviaría la escuela hacia un currículo predispuesto contra la tradición occidental? La respuesta, sin duda, es "No". Los ciudadanos multiculturales de Canadá son canadienses, no son ciudadanos filipinos, chinos o indios orientales. Los jóvenes canadienses vivirán en Canadá, a no ser que adopten una nueva ciudadanía y vivan en cualquier otro lugar. El currículo escolar, y la suma total de las experiencias de los estudiantes, no puede sino prepararles para la vida en la sociedad canadiense. De esta forma, en la escuela orientada multiculturalmente, lo que se entiende por desarrollar la educación para la ciudadanía, tendrá que mantener necesariamente buena parte

43 Por ejemplo R. Griffith, Educational Citizenship and Independent Learning (London: Jessica Kingsley Publishers, 1998); C.L. Hahn, Becoming Political (New York: State University of New York Press, 1998); C. Holden and N. Clough, Children as Citizens: Education for Participation (London: Jessica Kingsley Publishers, 1998). 
de lo que se ha proporcionado en las escuelas canadienses. El currículo no debería aspirar sólo a desarrollar individuos educados (que son ciudadanos en potencia), tal como los caracteriza R.S. Peters, sino que debería también iniciar a la gente joven en esas habilidades, actitudes y hábitos que promoverán un compromiso responsable y satisfactorio en el mundo del trabajo y en la participación en la vida social y política dentro del marco canadiense. ${ }^{44}$ Por lo tanto, una educación con orientación multicultural que fomente la ciudadanía no requiere rehacer la escuela actual. No exige la supresión de las asignaturas típicas de Canadá. El currículo necesario será un currículo inclusivo, que esté ideado creativamente para acomodar, dentro del currículo habitual, el estudio de las diversas culturas del país y de los derechos y responsabilidades ciudadanas de los individuos y los grupos que componen la sociedad. También recogerá experiencias variadas -curriculares y extra-curriculares - que promoverán la interacción entre individuos de distintos grupos culturales, de forma que proporcionen oportunidades para el aprendizaje cooperativo, la comprensión y el respeto a los otros, y entrenarán en el arte de la vida democrática participativa.

¿La educación para la ciudadanía en una sociedad multicultural, prevista en el contexto canadiense, impedirá el desarrollo del cosmopolitismo, que parece requerido por la globalización de los distintos aspectos de la vida humana, al menos en las sociedades económicamente avanzadas? La respuesta podría ser perfectamente, "no de manera necesaria". En la medida en la que la escuela proporciona la educación que, entre otros, demanda nuestro modelo, podrá esperarse que los educandos dentro de las escuelas canadienses posean amplios conocimientos y perspectivas que les capaciten no sólo para dar sentido a la vida humana en el complejo e interconectado mundo contemporáneo, sino también para responder a sus exigencias de forma satisfactoria. Podría ocurrir que, debido a su énfasis en el estudio de la diversidad cultural, la educación para la ciudadanía en una sociedad multicultural contribuya positivamente al desarrollo de gente joven capacitada para afrontar los cambios de trabajo y de vida en distintos ambientes culturales, ya sea en el propio país o en el extranjero. Es también importante señalar que los principios elementales de la política canadiense de multiculturalismo, por no hablar de los derechos y libertades fundamentales protegidos por la Constitución Canadiense, son los mismos principios, derechos y libertades proclamados en los documentos internacionales de derechos humanos aprobados por las Naciones Unidas. El estudio en profundidad del currículo requerido por el modelo canadiense puede, por tanto, esperarse que satisfaga las necesidades del cosmopolitismo emergente.

44 R. Peters, Ethics and Education (London: Allen and Unwin, 1966). 